\title{
Genotypic characterisation and cluster analysis of Campylobacter jejuni isolates from domestic pets, human clinical cases and retail food
}

\author{
Els Acke ${ }^{1,2,7^{*}}$, Cyril Carroll ${ }^{3}$, Aoife O'Leary ${ }^{3}$, Kevina McGill1', Lorraine Kelly', Amanda Lawlor ${ }^{2}$, Robert H Madden ${ }^{4}$, \\ Lynn Moran ${ }^{4}$, Pam Scates ${ }^{4}$, Eleanor McNamara ${ }^{5}$, John E Moore ${ }^{6}$, Boyd R Jones², Seamus Fanning ${ }^{1}$ and \\ Paul Whyte
}

\begin{abstract}
The genetic similarity of Campylobacter jejuni isolates from pets, compared to human clinical cases and retail food isolates collected in Ireland over 2001-2006 was investigated by cluster analysis of pulsed-field gel electrophoresis (PFGE) fingerprinting profiles. Comparison of the PFGE profiles of 60 pet isolates and 109 human isolates revealed that seven (4.1\%) profiles were grouped in clusters including at least one human and one pet $C$. jejuni isolate. In total six (1.6\%) of 60 pet and 310 food profiles were in clusters with at least one food and one pet C. jejuni isolate. The detection of only a small number of genetically indistinguishable isolates by PFGE profile cluster analysis from pets and from humans with enteritis in this study suggests that pets are unlikely to be an important reservoir for human campylobacteriosis in Ireland. However, genetically indistinguishable isolates were detected and C. jejuni from pets may circulate and may contribute to clinical infections in humans. In addition, contaminated food fed to pets may be a potential source of Campylobacter infection in pets, which may subsequently pose a risk to humans.
\end{abstract}

\section{Background}

A major source of Campylobacter infections in humans is the handling or consumption of contaminated meat, especially poultry. Other risk factors for infection include ingestion of contaminated dairy products (for example unpasteurised milk), drinking contaminated water, contact with pets, foreign travel, and swimming in natural sources of water [1-3]. It is estimated that C. jejuni accounts for approximately $80-95 \%$ of all enteric Campylobacter infections in humans, with C. coli, C. lari, C. upsaliensis and C. fetus less commonly isolated [4,5]. Many questions on the epidemiology of Campylobacter spp. remain unanswered due to the high degree of genetic diversity observed in Campylobacter spp. populations [6,7], the low number of isolates in which speciation and subtyping is performed [8], the under reporting of cases because of the self-limiting nature of Campylobacter infections in most individuals [9], and the fact that

\footnotetext{
* Correspondence: E.Acke@massey.ac.nz

${ }^{1}$ Centre for Food Safety, School of Agriculture, Food Science and Veterinary

Medicine, University College Dublin, Belfield, Dublin 4, Ireland

Full list of author information is available at the end of the article
}

most cases of human campylobacteriosis are sporadic as opposed to large outbreaks [10]. Contact with pets has been recognised as a risk factor for campylobacteriosis in humans $[1,11,12]$. Pets have been shown to be carriers of Campylobacter spp. with C. upsaliensis, C. jejuni and C. helveticus the predominant species isolated [13-16]. Although C. upsaliensis was the most commonly isolated Campylobacter spp. from household pets in Ireland with a prevalence of $65 \%$, C. jejuni was also frequently isolated (22.5\%) [16]. Wolfs et al. [17] reported the first genetically proven case of $C$. jejuni transmission between pets and humans in a 3-week-old infant who acquired the infection from a recently obtained household puppy with diarrhoea. Damborg et al. [18] reported the occurrence of identical C. jejuni strains in a 2-year-old girl and her dog in Denmark confirmed by PFGE. With reported Campylobacter spp. isolation rates of up to $87 \%$ and $75 \%$ in dogs and cats respectively in Ireland $[15,16]$, pets could play a substantial role in the epidemiology of campylobacteriosis. The aim of this retrospective study was to compare the genotypes from pet $C$. jejuni isolates to a large number of human clinical and retail food $C$. jejuni
C Biomed Central

() 2011 Acke et al; licensee BioMed Central Ltd. This is an Open Access article distributed under the terms of the Creative Commons Attribution License (http://creativecommons.org/licenses/by/2.0), which permits unrestricted use, distribution, and reproduction in any medium, provided the original work is properly cited. 
genotypes obtained on the island of Ireland and to assess if isolates from different sources were indistinguishable, based on PFGE profile cluster analysis.

\section{Methods}

C. jejuni isolates from pets included in this study $(\mathrm{n}=60)$ were collected from Irish cats and dogs in shelters and private households as part of a large Campylobacter spp. prevalence study. The majority of cats and dogs sampled lived in the Dublin area and Belfast. Healthy pets and pets with signs of gastro-intestinal disease were included in the study $[7,15,16]$. One rectal swab was obtained from each animal and swabs were cultured using a range of specialised culture methods to optimise recovery of Campylobacter spp. [19]. DNA was extracted and Campylobacter speciation was performed by PCR analysis at the Centre for Food Safety at University College of Dublin (UCD) as previously described [15]. As part of a Food Safety Promotion Board-funded (FSPB) project, retail food samples were collected from a range of supermarkets and butcher shops in three regions in Ireland: Dublin, Galway and Belfast. The majority of the samples included in the present study were from poultry meat. Sampling procedures and Campylobacter isolation techniques used for food analysis are described by Whyte et al. [20]. Concurrently with the isolation of the food isolates, Campylobacter isolates from human clinical cases were submitted by collaborating Public Health Laboratories in Dublin, Galway and Belfast. These isolates were obtained from patients who had presented to either general practitioners or had been admitted to hospitals with signs of gastro-enteritis. All C. jejuni human clinical, food and pet isolates were collected between 2001-2006. Genotyping was performed using PFGE at the Enteric Pathogen Research Laboratory, National University of Ireland, Galway. All C. jejuni isolates obtained from pets were genotyped using identical methods at the Centre for Food Safety, UCD. PFGE profiling of the $C$. jejuni isolates was carried out using the standardised 'Campynet' protocol as previously described [21]. The restriction enzyme used was SmaI (R6125, ProMega, USA). PFGE gels obtained after electrophoresis were captured in a TIFF format by using a GelDoc 1000 high-resolution image capture system (Bio-Rad).

A database of genotypes of the pet, retail food and human clinical C. jejuni isolates was subsequently assembled at the Centre for Food Safety, UCD [22,23]. PFGE profiles were analysed using Fingerprinting II software, Bionumerics Version 3.0 (Applied Maths, Kortrijk, Belgium). A combination of Dice and UPGMA (unweighted paired group method with arithmetic mean), position tolerance value of $1.5 \%$ and an optimisation value of $1.0 \%$ was used [24]. Clusters were defined as isolates with at least $90 \%$ genetic similarity. These isolates were considered indistinguishable.

\section{Results and Discussion}

The genotypic relatedness of $C$. jejuni isolates obtained from pets and those obtained from human clinical and retail food samples in Ireland were determined by PFGE profile cluster analysis. Cluster analysis of 60 pet C. jejuni profiles compared to 109 human clinical C. jejuni profiles showed $4.1 \%$ of isolates were in clusters containing at least one pet and one human isolate. One cluster of three included two isolates from adults with gastroenteritis in Belfast and an adult dog with no signs of gastro-intestinal disease from the Dublin area. There were two clusters each containing two isolates; one of these contained isolates from an adult with gastro-enteritis in Galway and from a healthy shelter puppy in the Dublin area. The other cluster contained isolates from an adult with gastro-enteritis in Galway and a household puppy from Dublin with diarrhoea. The occurrence of genetically indistinguishable $C$. jejuni isolates appears to be uncommon when Irish pet isolate profiles were compared to human isolate profiles. The present study included isolates from different sources collected over several years and in different regions of Ireland, making it less likely that common isolates were present and further investigations on pets as a potential reservoir for human campylobacteriosis are indicated. The true prevalence world wide of indistinguishable isolates occurring in pets and humans may be underestimated due to a number of factors including the under reporting of infections, lack of epidemiological studies including animals, the occurrence of mixed C. jejuni populations, intermittent excretion of campylobacters [25], and the high level of genetic diversity in C. jejuni populations $[7,26]$. The study design plays an important role and no large-scale studies have been performed to date evaluating human clinical cases of campylobacteriosis concurrently with Campylobacter spp. detected from pets in their environment. Additional epidemiological links could also exist between $C$. jejuni isolates from different sources if other enzymes for PFGE are used, or due to small genetic rearrangements in the organisms $[18,27]$.

The handling and consumption of contaminated meat, especially poultry, has long been implicated as a major source of campylobacteriosis in humans [3,10,28]. Food may also play an important role in Campylobacter spp. colonisation in pets, which may consequently result in human infection [29], and food as a common source of infection in pets and humans could be possible. Also drinking unpasteurised milk or contaminated water, and direct (fresh faeces) or indirect (contaminated food bowls, environment) contact with infected animals can be a 


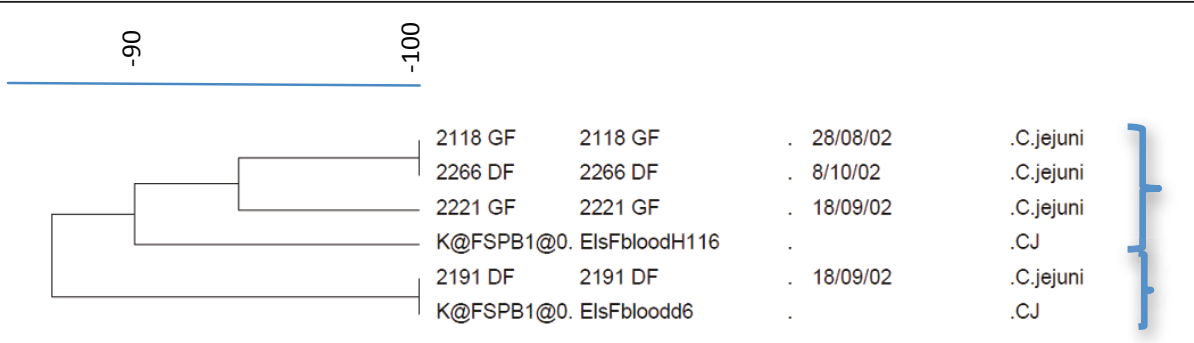

Figure 1 Clusters of $\boldsymbol{C}$. jejuni isolates. (i) A cluster of four with a dog isolate (H116), and three food sample isolates (2118GF, 2266DF, 2221GF) and (ii) a cluster of two with a food sample isolate (2191DF) and a shelter puppy isolate (d6). The scale indicates percentage genetic similarity.

source of infection in pets [29]. Genotypic comparisons of C. jejuni isolate PFGE profiles from pets to a large number of food isolate profiles has not been reported previously. Cluster analysis of 60 pet C. jejuni profiles compared to 310 retail food $C$. jejuni profiles obtained by PFGE showed $1.6 \%$ of isolates were in clusters. One cluster of four containing an isolate from cow's liver sampled in Galway, an isolate from lamb's heart sampled in Dublin, a Galway chicken isolate and an isolate from an adult dog with no signs of gastro-intestinal disease from the Dublin area. One cluster of two isolates was detected comprising a Dublin chicken isolate and an isolate from a healthy shelter puppy in the Dublin area (Figure 1). The two pet isolates that clustered with the food isolates were the same as two out of three that clustered with the human clinical isolates. With the low number of pet and food isolates that clustered based on PFGE profile analysis, retail food appears an unlikely source of Campylobacter infections in pets. However, the feeding habits in the households and shelters where the pets lived were unknown and a possible direct link between feeding contaminated retail foods to pets and Campylobacter spp. isolation was not assessed in the present study.

The epidemiology of campylobacteriosis is highly complex due to the many animal and environmental reservoirs [30]. In addition, a high level of genetic diversity between isolates from pets has now also been confirmed $[7,26]$. Since Campylobacter spp. are zoonotic pathogens and asymptomatic animals could act as reservoirs, pets in contact with people with increased risk of infection (e.g., immunocompromised children) may represent an important health risk and adequate hygiene practices in households with pets are essential [31]. Adequate hygiene measures are required also when feeding pets meat or other potentially contaminated foods. Further studies involving larger populations, a variety of sampling groups, testing for multiple Campylobacter spp., and specialised molecular techniques are indicated to clarify the role of pets in human campylobacteriosis and to improve the understanding of the complex epidemiology of Campylobacter infections.

\section{Conclusions}

The detection of indistinguishable PFGE profiles of $C$. jejuni obtained from pets, human clinical cases and retail food samples in different geographical regions on the island of Ireland, collected over several years, suggests that isolates may circulate between different sources. The presence of a small number of clusters containing isolates from dogs and human clinical cases makes it unlikely that pets represent a substantial risk for human campylobacteriosis, however, further investigations aimed specifically at confirmation of zoonotic transmission are required.

\section{Acknowledgements}

The authors dedicate this manuscript to Ms Lorraine Kelly, who unfortunately passed away in 2008. Without her input this work would not have been possible. We also thank all staff of the University Veterinary Hospital, UCD for their help with the sample collection. Thank you to the personnel in the Centre for Food Safety and the Veterinary Microbiology Laboratory, UCD for their help with the processing of the samples. The authors also acknowledge Small Animal Clinical Studies, UCD, and 'safefood' for funding this investigation.

\section{Author details}

${ }^{1}$ Centre for Food Safety, School of Agriculture, Food Science and Veterinary Medicine, University College Dublin, Belfield, Dublin 4, Ireland. ${ }^{2}$ Small Animal Clinical Studies, School of Agriculture, Food Science and Veterinary Medicine, University College Dublin, Belfield, Dublin 4, Ireland. ${ }^{3}$ Enteric Pathogen Research Laboratory, Department of Microbiology, National University of Ireland, Galway, Ireland. ${ }^{4}$ Agri-Food and Biosciences Institute, Newforge Lane, Belfast, Northern Ireland, UK. ${ }^{5}$ Public Health Laboratory, Cherry Orchard Hospital, Ballyfermot, Dublin 10, Ireland. ${ }^{6}$ Northern Ireland Public Health Laboratory, Department of Bacteriology, Belfast City Hospital, Belfast BT9 7AD, Northern Ireland, UK. 7Veterinary Teaching Hospital, Institute of Veterinary, Animal and Biomedical Sciences, Private Bag 11222 Massey University, Palmerston North 4442, New Zealand.

\section{Authors' contributions}

EA drafted the work, performed pet sample collection, bacterial cultures and molecular work including PFGE of C. jejuni and the cluster analysis of the pet isolates, CC and AOL performed the sample collection, bacterial cultures and molecular work including PFGE of the Galway human clinical and retail food isolates, KMG and EMN participated in bacterial cultures and molecular work of Dublin pet, human clinical and retail food isolates, LK performed the cluster analysis of the C. jejuni isolates obtained from human clinical cases and retail food and assembled the database at the Centre for Food safety, AL participated in the PFGE of pet isolates, RHM, LM, PS, and JEM performed the sample collection, bacterial cultures and molecular work including PFGE of the Belfast human clinical and retail food isolates BRJ, SF and PW were involved in the revision of the manuscript, the project design and the 
analysis and interpretation of the data assembled in this work. All authors read and approved the final manuscript.

\section{Competing interests}

The authors declare that they have no competing interests.

Received: 1 October 2010 Accepted: 31 March 2011

Published: 31 March 2011

\section{References}

1. Adak GK, Cowden JM, Nicholas S, Evans HS: The Public Health Laboratory Service national case-control study of primary indigenous sporadic cases of campylobacter infection. Epidemiol Infect 1995, 115:15-22.

2. Schönberg-Norio D, Takkinen J, Hanninen ML, Katila ML, Kaukoranta SS, Mattila L, Rautelin H: Swimming and Campylobacter infections. Emerg Infect Dis 2004, 10:1474-1477.

3. Anonymous: Campylobacteriosis in Ireland, 2005. Health Protection Surveillance Centre; 2006, 34-36 [http://www.hpsc.ie].

4. Newell DG, Frost JA, Duim B, Wagenaar JA, Madden RH, Van Der Plas J, On SLW: New developments in the subtyping of Campylobacter species. In Campylobacter. Edited by: Nachamkin I, Blaser MJ. Washington DC, ASM Press: 2000:27-44.

5. Moore JE, Corcoran D, Dooley JS, Fanning S, Lucey B, Matsuda M, McDowell DA, Megraud F, Millar BC, O'Mahony R, O'Riordan L, O'Rourke M, Rao JR, Rooney PJ, Sails A, Whyte P: Campylobacter. Vet Res 2005, 36:351-382.

6. Dingle KE, Colles FM, Ure R, Wagenaar JA, Duim B, Bolton FJ, Fox AJ, Wareing DR, Maiden MC: Molecular characterization of Campylobacter jejuni clones: a basis for epidemiologic investigation. Emerg Infect Dis 2002, 8:949-955.

7. Acke E, McGill K, Jones BR, Fanning S, Whyte P: Genetic diversity among Campylobacter jejuni isolates from pets in Ireland. Vet Rec 2010, 166:102-106.

8. Moore JE, Matsuda M: The History of Campylobacter: Taxonomy and Nomenclature. Ir Vet J 2002, 55:495-501.

9. Snelling WJ, Matsuda M, Moore JE, Dooley JS: Campylobacter jejuni. Lett Appl Microbiol 2005, 41:297-302.

10. Mazick A, Ethelberg S, Nielsen EM, Molbak K, Lisby M: An outbreak of Campylobacter jejuni associated with consumption of chicken, Copenhagen, 2005. Euro Surveill 2006, 11(5):137-9.

11. Tenkate TD, Stafford RJ: Risk factors for campylobacter infection in infants and young children: a matched case-control study. Epidemiol Infect 2001, 127:399-404.

12. Carrique-Mas J, Andersson $Y$, Hjertqvist M, Svensson A, Torner A, Giesecke J: Risk factors for domestic sporadic campylobacteriosis among young children in Sweden. Scand J Infect Dis 2005, 37:101-110.

13. Wieland B, Regula G, Danuser J, Wittwer M, Burnens AP, Wassenaar TM, Stark KD: Campylobacter spp. in dogs and cats in Switzerland: risk factor analysis and molecular characterization with AFLP. J Vet Med B 2005, 52:183-189.

14. Workman SN, Mathison GE, Lavoie MC: Pet dogs and chicken meat as reservoirs of Campylobacter spp. in Barbados. J Clin Microbiol 2005, 43:2642-2650.

15. Acke E, Whyte P, Jones BR, McGill K, Collins JD, Fanning S: Prevalence of thermophilic Campylobacter species in cats and dogs in two animal shelters in Ireland. Vet Rec 2006, 158:51-54.

16. Acke E, McGill K, Golden O, Jones BR, Fanning S, Whyte P: Prevalence of Campylobacter species in household pets in Ireland. Vet Rec 2009 164:44-47.

17. Wolfs TF, Duim B, Geelen SP, Rigter A, Thomson-Carter F, Fleer A Wagenaar JA: Neonatal sepsis by Campylobacter jejuni: genetically proven transmission from a household puppy. Clin Infect Dis 2001, 32 E97-99.

18. Damborg P, Olsen KE, Moller Nielsen E, Guardabassi L: Occurrence of Campylobacter jejuni in pets living with human patients infected with C. jejuni. J Clin Microbiol 2004, 42:1363-1364

19. Acke E, McGill K, Jones BR, Fanning S, Whyte P: A comparison of different culture methods for the recovery of Campylobacter species from pets. Zoonoses Public Health 2009, 56:490-495.

20. Whyte P, McGill K, Cowley D, Madden RH, Moran L, Scates P, Carroll C, O'Leary A, Fanning S, Collins JD, McNamara E, Moore JE, Cormican M:
Occurrence of Campylobacter in retail foods in Ireland. Int J Food Microbiol 2004, 95:111-118

21. Campynet 2001: [http://campynet.vetinst.dk/].

22. Kelly L: A study of the Epidemiology and Antimicrobial Resistance of Campylobacter in the Irish Food Chain and Human population. MSC thesis National University of Ireland, Centre for Food Safety; 2006.

23. Acke E: A study of thermophilic campylobacters from domestic cats and dogs in Ireland. PhD thesis National University of Ireland, Small Animal Clinical Studies; 2007.

24. Anonymous: BioRad Fingerprinting II Software User Guide. version 3.0 BioRad, Hercules, Ca., USA; 2002.

25. Hald B, Pedersen K, Waino M, Jorgensen JC, Madsen M: Longitudinal study of the excretion patterns of thermophilic Campylobacter spp. in young pet dogs in Denmark. J Clin Microbiol 2004, 42:2003-2012.

26. Parsons BN, Cody AJ, Porter CJ, Stavisky JH, Smith JL, Williams NJ, Leatherbarrow AJH, Hart CA, Gaskell RM, Dingle KE, Dawson S: Typing of Campylobacter jejuni isolates from dogs using multilocus sequence typing and pulsed field gel electrophoresis. J Clin Microbiol 2009, 47:3466-3471.

27. On SL: In vitro genotypic variation of Campylobacter coli documented by pulsed-field gel electrophoretic DNA profiling: implications for epidemiological studies. FEMS Microbiology Lett 1998, 165:341-346.

28. Adak GK, Meakins SM, Yip H, Lopman BA, O'Brien SJ: Disease risks from foods, England and Wales, 1996-2000. Emerg Infect Dis 2005, 11:365-372.

29. Fox JG: Enteric bacterial infections: Campylobacter, gastric Helicobacter and intestinal and hepatic Helicobacter infections. In Infectious diseases of the dog and cat Edited by: Greene CE. W.B. Saunders Company, 3 2006, 339-354

30. Devane ML, Nicol C, Ball A, Klena JD, Scholes P, Hudson JA, Baker MG, Gilpin BJ, Garrett N, Savill MG: The occurrence of Campylobacter subtypes in environmental reservoirs and potential transmission routes. $J$ Appl Microbiol 2005, 98:980-990.

31. Hemsworth S, Pizer B: Pet ownership in immunocompromised children a review of the literature and survey of existing guidelines. Eur J Oncol Nurs 2006, 10:117-127.

doi:10.1186/2046-0481-64-6

Cite this article as: Acke et al:: Genotypic characterisation and cluster analysis of Campylobacter jejuni isolates from domestic pets, human clinical cases and retail food. Irish Veterinary Journal 2011 64:6.

\section{Submit your next manuscript to BioMed Central and take full advantage of:}

- Convenient online submission

- Thorough peer review

- No space constraints or color figure charges

- Immediate publication on acceptance

- Inclusion in PubMed, CAS, Scopus and Google Scholar

- Research which is freely available for redistribution

Submit your manuscript at www.biomedcentral.com/submit
C Biomed Central 